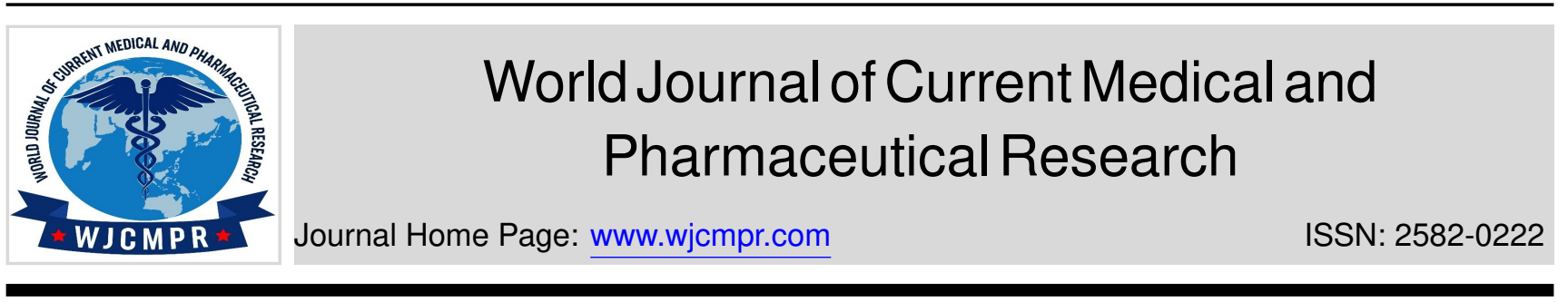

\title{
A descriptive review on patient medication history interview
}

\author{
Lankipalli Vinay Sai ${ }^{1, *}$, Venkata Ramana ${ }^{2}$, K Mamatha $^{1}$, D Saritha ${ }^{1}$, Jerusha Evagelin ${ }^{3}$, \\ Kummiti Veenasri ${ }^{4}$, Challa Divya Jyothi. ${ }^{4}$ \\ 1. Clinical Pharmacist, RDT Hospital, Bathalapalli, Ananthapuramu, Tel.: +91-8919172701 \\ 2. MBBS, DNB, Department of Family Medicine, RDT Hospital, Bathalapalli, Ananthapuramu \\ 3. MBBS, DGO, (DNB), Post Graduate, Department of Obstetrics and Gynaecology, RDT Hospital, Bathalapalli, Ananthapuramu \\ 4. Pharm.D Intern, RDT Hospital, Bathalapalli, Ananthapuramu
}

\section{ARTICLE INFO}

Article history:

Received 22.12.2020

Accepted 01.02.2021

Published 15.02.2021

* Corresponding Author:

Lankipalli Vinay Sai

Lankipallivinaysai@gmail.com

https://doi.org/

10.37022/wjcmpr.vi.163

Produced By

South Asian Academic

Publications

\begin{abstract}
A B S T R A C T
The Present descriptive review provides a detailed practical approach in conducting the effective patient medication interview. It includes four main area, 1) the process involved and goals to be achieved, 2) importance of accurate patient drug history in patient medication history interview, 3 ) information to be recorded during patient medication history interview and 4) how to conduct patient medication interview in effective manner. This present review further attempted to give a clear pictorial representation regarding patient medication history interview as well produced a well-documented patient medication history interview form by referring all the available sources and thorough review of all available scientific literature.
\end{abstract}

Keywords: Patient medication history interview; drug history; pictorial representation; scientific literature.

\section{PATIENT MEDICATION HISTORY INTERVIEW:}

A medication history is a detailed, accurate and complete account of all prescribed and non-prescribed medications that a patient had taken or is currently taking prior to a newly initiated institutionalized or ambulatory care. It provides valuable insights into patients' allergic tendencies, adherence to pharmacological and non-pharmacological treatments, social drug use and probable self-medication with complementary and alternative medicines. Interviewing a patient in collecting the data medical history is called medication history interview $[1,2]$.

Goals of Patient medication history interview:

The goal of medication history interview is to obtain information on aspects of drug use that may assist in overall care of patient [3].

The information gathered can be utilized to:
- Compare medication profiles with the medication administration record and investigate the discrepancies.

- Verify medication history taken by other staffs and provide additional information where appropriate.

- Document allergies and adverse reactions.

- Screen for drug interactions.

- Assess patient medication compliance.

- Assess the rationale for drug prescribed.

- Assess the evidence of drug abuse.

- Appraise the drug administration techniques.

- Examine the needs for medication aids.

- Document patient-initiated medication administration. 
Importance of accurate Patient drug history in patient medication history interview [3]:

- Medication histories are important in preventing prescription errors and consequent risks to patients.

- Apart from preventing prescription errors, accurate medication histories are also useful in detecting drugrelated pathology or changes in clinical signs that may be the result of drug therapy.

- A good medication history should encompass all currently and recently prescribed drugs, previous adverse drug reactions including hypersensitivity reactions, any over-the counter medications, including herbal or alternative medicines, and adherence to therapy for the better health care plan.

- A full medication history.

- Identifies patients' needs.

- Explores the patient's perspective of illness and its treatment (needs and concerns)What is to be documented? To review current medical treatment and identify suitable additional treatments, medical professionals will require complete and reliable medication history.

\section{Information Recorded during patient medication history}

interview:

The following information is commonly recorded [4]:

- Currently or recently prescribed medicines.

- OTC medication.

- Vaccinations.

- Alternative or traditional remedies.

- Description of reaction and allergies to medicines.

- Medicines found to be ineffective.

- Adherence to past treatment courses and the use of adherence aids.

\section{THE PATIENT \& THE PHARMACISTS}

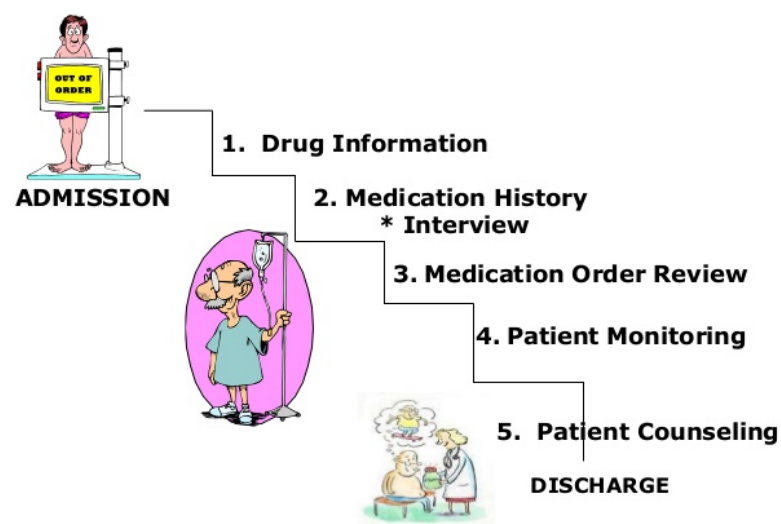

Fig 01: Representing the detailed process involved in achievement of desired therapeutic outcomes

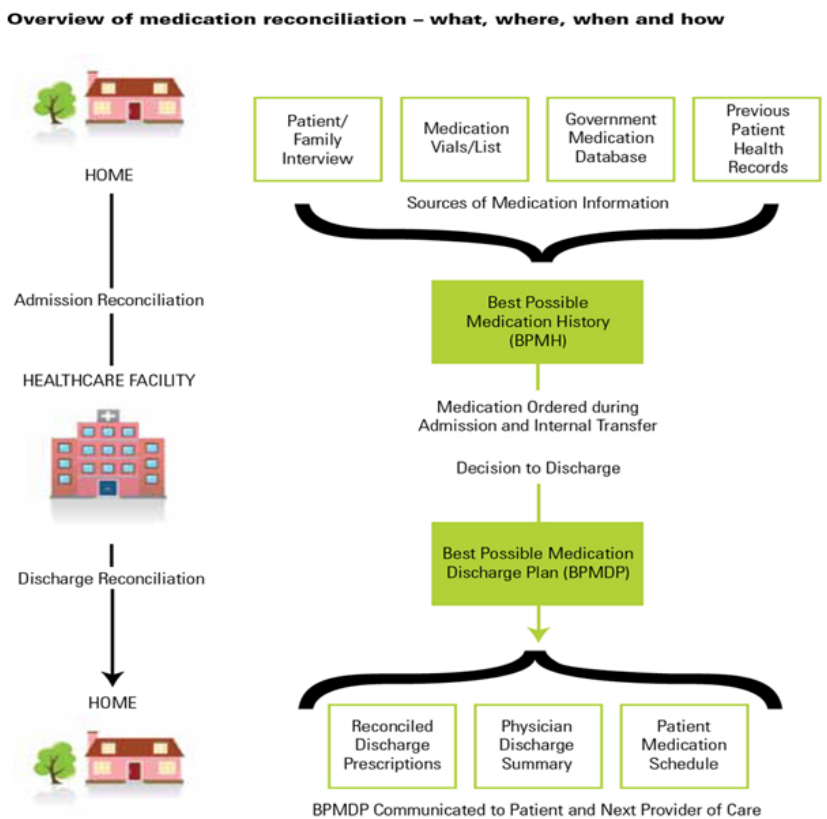

Fig 02: Representing the overview of patient medication reconciliation and its impact over patient medication history interview

\section{Interviewing the client/ patient during medication} history interview:

- Introduce yourself.

- Inform client of reason for you being there.

- Inform client of importance of maintaining a current medication list in chart Information sources.

\section{QUESTIONS to ASK to patient during medication} history interview [6-10]:

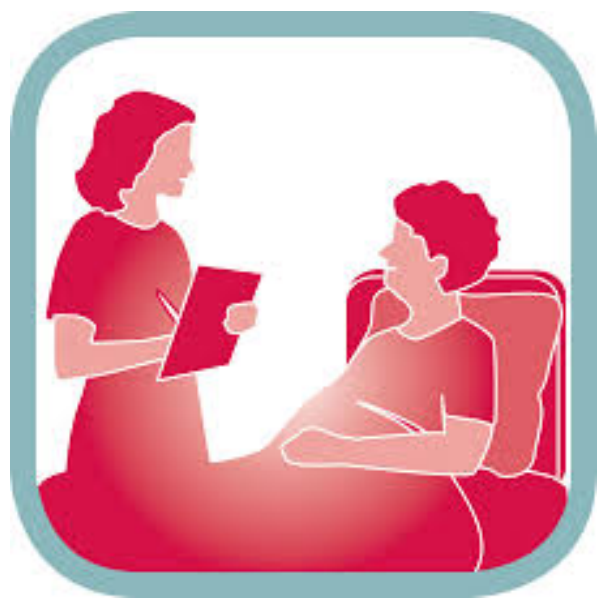

- Which community pharmacy do you use?

- Any allergies to medications and what was the reaction?

- Which medications are you currently taking?

- The name of the medication?

- The dosage form? 


\section{The Medical Interview Model}

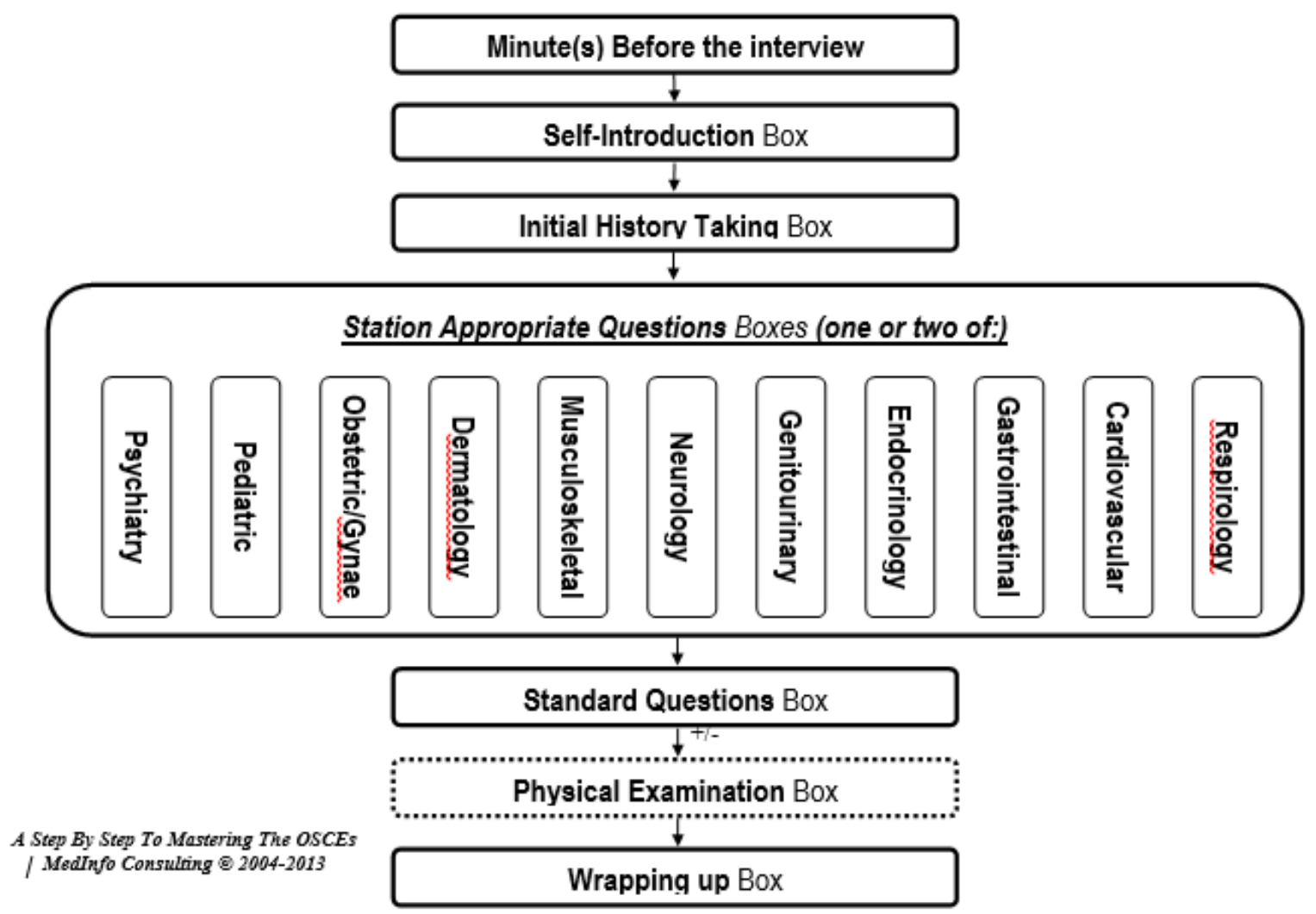

Fig 03: Representing the schematic Representation of medication interview model

- The amount (specifically the dose)?

- How are they taking it (by which route)?

- How many times a day?

- Any specific times?

- For what reason (if not known or obvious)?

- What prescription medications are you taking on a regular or as needed basis?

- What over the counter (non-prescription) medications are you taking on a regular or as needed basis?

- What herbal or natural medicines are you taking on a regular or as needed basis?

- What vitamins or other supplements are you taking?

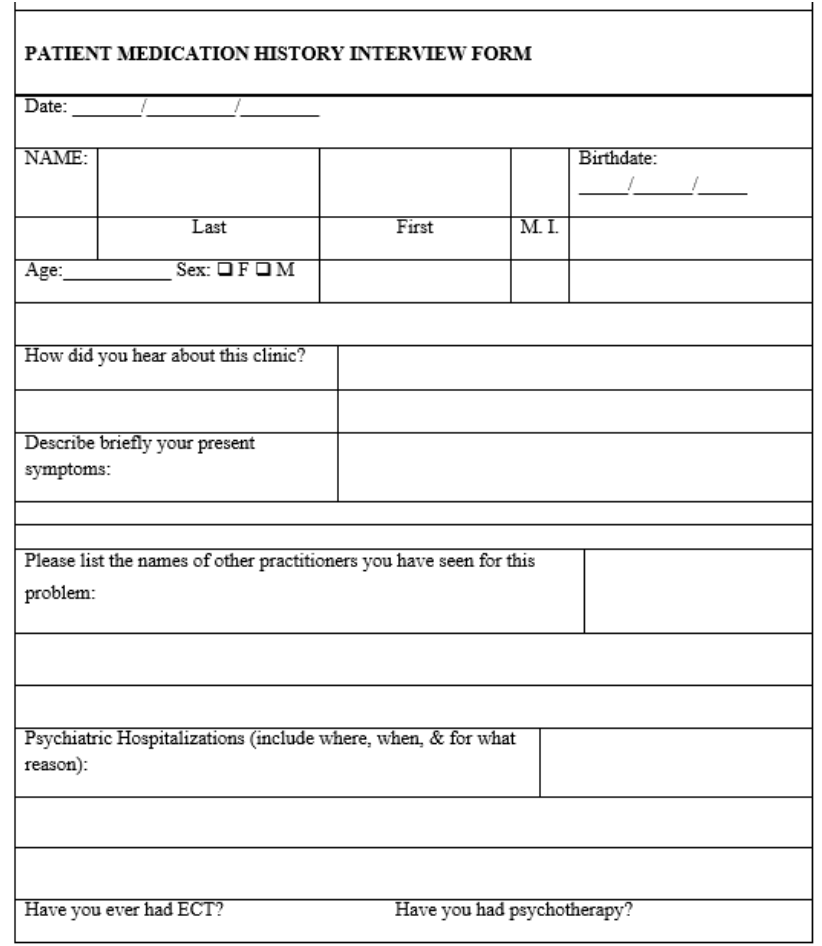




\begin{tabular}{|c|c|}
\hline \multicolumn{2}{|c|}{ CURRENT MEDICATIONS } \\
\hline \multicolumn{2}{|c|}{$\begin{array}{l}\text { Drug allergies: } \square \text { No } \square \text { Yes To } \\
\text { Please list any medications that you are now taking. Include non-prescription medications \& } \\
\text { vitamins or supplements: }\end{array}$} \\
\hline Name of drug & $\begin{array}{l}\text { Dose (include strength \& number of pills per day) How long } \\
\text { have you been taking this? }\end{array}$ \\
\hline \multicolumn{2}{|l|}{1.} \\
\hline \multicolumn{2}{|l|}{2.} \\
\hline \multicolumn{2}{|l|}{3.} \\
\hline \multicolumn{2}{|l|}{4.} \\
\hline \multicolumn{2}{|l|}{5.} \\
\hline \multicolumn{2}{|l|}{6.} \\
\hline \multicolumn{2}{|l|}{7.} \\
\hline \multicolumn{2}{|l|}{8.} \\
\hline \multicolumn{2}{|l|}{9.} \\
\hline \multicolumn{2}{|l|}{10.} \\
\hline \multicolumn{2}{|l|}{11.} \\
\hline 12. & \\
\hline
\end{tabular}

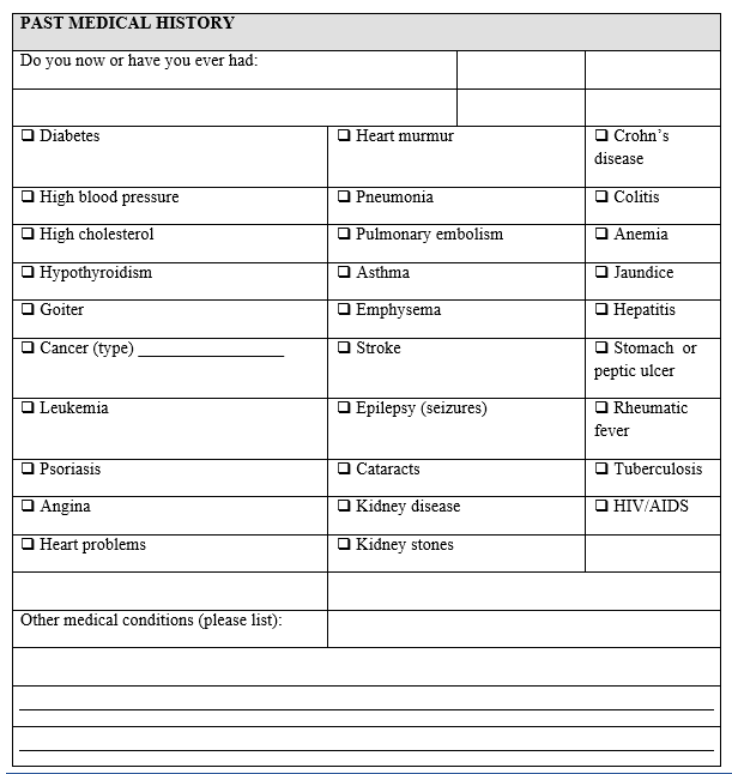

\begin{tabular}{|c|c|c|c|}
\hline \multicolumn{4}{|l|}{ PERSONAL HISTORY } \\
\hline \multicolumn{4}{|l|}{$\begin{array}{l}\text { Were there problems with your } \\
\text { birth? (specify) }\end{array}$} \\
\hline \multicolumn{4}{|l|}{$\begin{array}{l}\text { Where were your born \& } \\
\text { raised? }\end{array}$} \\
\hline $\begin{array}{l}\text { What is your highest } \\
\text { education? }\end{array}$ & \multicolumn{3}{|c|}{$\begin{array}{l}\text { DHigh school } \square \text { Some college } \square \text { College graduate DAdvances } \\
\text { degree }\end{array}$} \\
\hline \multicolumn{4}{|c|}{$\begin{array}{l}\text { Marital status: } \square \text { Never married } \square \text { Married } \square \text { Divorced } \square \text { Separated } \square \text { Widowed } \square \\
\text { Partnered/significant other }\end{array}$} \\
\hline \multicolumn{4}{|c|}{ What is your current or past occupation? } \\
\hline \multicolumn{2}{|c|}{$\begin{array}{l}\text { Are you currently working? : } \square \text { Yes } \square \\
\text { No }\end{array}$} & \multicolumn{2}{|c|}{\begin{tabular}{l|l} 
Hours/week & $\begin{array}{l}\text { If not, are you } \square \text { retired } \square \text { disa } \\
\square \text { sick leave? }\end{array}$
\end{tabular}} \\
\hline \multicolumn{2}{|c|}{ Do you receive disability or SSI? Y Yes No } & \multicolumn{2}{|c|}{ If yes, for what disability \& how long? } \\
\hline \multicolumn{4}{|c|}{ Have you ever had legal problems? (specify) } \\
\hline Religion: & & & \\
\hline
\end{tabular}

\begin{tabular}{|l|l|l|l|l|}
\hline \multicolumn{3}{|c|}{ FAMILY HISTORY } \\
\hline & Age (s) & Health \& Psychiatric & $\begin{array}{c}\text { Age(s) at } \\
\text { death }\end{array}$ & \\
\hline Father & & & & \\
\hline Mother & & & & \\
\hline Siblings & & & & \\
\hline $\begin{array}{l}\text { Childre } \\
\text { n }\end{array}$ & & & & \\
\hline EXTENDED FAMILY PSYCHIATRIC PROBLEMS PAST \& PRESENT: \\
\hline Maternal Relatives: \\
\hline \multicolumn{5}{|l}{} \\
\hline Paternal Relatives: \\
\hline
\end{tabular}

\section{CONCLUSION}

The patient medication history interview is an important step that needed to be carried out in effective manner as it aids in promotion of desired therapeutic outcome in the field of therapeutic management of various disorders/diseases. We hope the present review will greatly helpful for the quick and easy reference of how to conduct the patient medication history interview and further involved in providing a clear picture of its importance in achievement of desired therapeutic outcomes.

\section{Author Contribution}

All authors Contributed Equally.

\section{REFERENCES}

1) Wingate D, Phillips SF, Lewis SJ, Malagelada JR, Speelman P, Steffen R, et al. Guidelines for adults on self-medication for the treatment of acute diarrhoea. Alimentary Pharmacology \& Therapeutics. 2001;15(6):773782. Available from: https://dx.doi.org/10.1046/j.1365-2036.2001. 00993.x.

2) Horn JR, Philip DH. Loperamide: Danger of Elevated Plasma Concentrations. 2016.

3) Mehran ZMD, Maryam RMD. Loperamide Dependency: A Case Report. Addict Health. 2017;9(1):59-63.

4) National Institute on Drug Abuse, Advancing Addiction Science, OvertheCounter Medicines Antidiarrheal medication. Loperamide Health Effects. .

5) Wagner GA, de Andrade AG. Pharmacist professionals in the prevention of drug abuse: updating roles, and opportunities. Brazilian Journal of Pharmaceutical Sciences. 2010;46(1):19-27. Available from: https://dx.doi.org/10.1590/s1984-82502010000100003.

6) Chris EMA. Substance abuse Counseling Techniques. 2018.

7) Healthday: Some addicts abusing diarrhea drug Imodium, Addicts are turning to Imodium for its key ingredient, loperamide. Article no.156.

8) Daniulaityte R, Carlson R, Falck R, Cameron D, Perera S, Chen L, et al. "I just wanted to tell you that loperamide WILL WORK": A webbased study of extra-medical use of loperamide. Drug and Alcohol Dependence. 2013;130(1-3):241-244. Available from: https://dx.doi. org/10.1016/j.drugalcdep.2012.11.003.

9) Lavin MR, Marraffa JM, Holland MG, Sullivan RW, Morgan BW, Oakes JA, et al. Cardiac conduction disturbance after loperamide abuse. Depress Anxiety. 1996;4(5):952-959.

10) Prescription vs. OTC: Loperamide Information/ FDA label. 